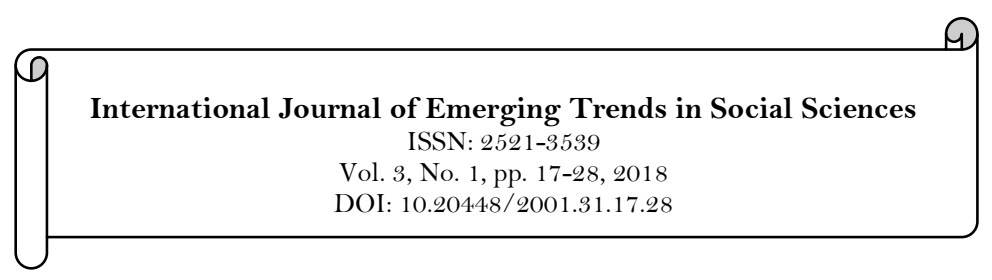

\title{
Using Gender Inequality to Predict the Rate of African Women Entrepreneurship
}

\author{
Michael Uche Udanoh ${ }^{1 *}$ \\ Ayoub Zouria ${ }^{2}$ \\ $\mathbf{\bullet}_{1,2}$ School of Business Administration, Zhejiang Gongshang University, Hangzhou, China. \\ ${ }^{2}$ Email:udanohmichael@outlook.com \\ ${ }^{2}$ Email:avoub.zouria@yahoo.com
}

\begin{tabular}{|c|c|}
\hline Abstract & \\
\hline $\begin{array}{l}\text { Entrepreneurship has been closely linked to the economic } \\
\text { development of countries. The level of contribution that } \\
\text { entrepreneurial activity has on an economy is dependent on factors } \\
\text { such as competency, gender composition, and the type and level of } \\
\text { developed entrepreneurship. Gender equality and female } \\
\text { entrepreneurial activity are closely associated with the economic } \\
\text { development of a country. In past research, it has been noted there is } \\
\text { a negative association between the level of national income and the } \\
\text { rate of female entrepreneurial development rate. The study } \\
\text { investigates the association between gender inequality and the rate of } \\
\text { women entrepreneurial development for twelve African countries. It } \\
\text { uses gender-related variables and indices drawn from internationals } \\
\text { databases to analyze the relationship they have to women } \\
\text { entrepreneurial activity. Data from Global Entrepreneurship } \\
\text { Monitor (GEM) on different stages of African women } \\
\text { entrepreneurship development was used in the research. }\end{array}$ & $\begin{array}{l}\text { Keywords: } \\
\text { Entrepreneurship } \\
\text { Women } \\
\text { Gender } \\
\text { Inequality. } \\
\text { Licensed: } \\
\text { This work is licensed under a } \\
\text { Creative Commons Attribution } \\
\text { 4.0 License. } \\
\text { Publisher: } \\
\text { Scientific Publishing Institute }\end{array}$ \\
\hline
\end{tabular}

\section{Introduction}

\subsection{Background}

Entrepreneurial activity is closely linked to economic growth with recognized contribution to job creation, revenue generation, poverty alleviation and wealth generation (Olutunla, 2001). Enterprise organizations that have high financial performance contribute immensely to the regional, national, or global economies (Naudé, 2013). Entrepreneurship is thus identified as the central element in the theory of economic development. Continued research on entrepreneurship is carried out to enhance entrepreneurial activities as well as increase the performance of established enterprises. Globally, differences in the level of entrepreneurial development have been attributed to the variances in social, cultural, technological, institutional, and economic development levels. Social-cultural factors are associated mainly revolve around gender differences within a community as well as at the individual level. The link between gender and enterprise development has been explored and identified as a crucial consideration for entrepreneurial research. Over the past years, gender variable shave been used to explain the demographic patterns in relation to motivation on entrepreneurship behavior. The tendency of indulging into an entrepreneurial activity is closely linked to the social-cultural development of a person.

The economic decisions of an entrepreneur are, along with other factors, heavily guarded by the cultural standards and norms. Studies on African culture have continued to indicate a great disparity in relation to gender equality indexes based on economic, human, and institutional development. Analyzing the relationship between the African women and the level of entrepreneurial development sheds light on the various factors that affect them in establishing and successfully running economic organizations. In the study, gender-related factors such as gender inequality, gender stereotyping, and gender-based beliefs are the independent variables. The rate of the entrepreneurial development of African women is the dependent variable. Mediating and moderating variables are also used in this research. Access to education provides a moderating factor to the negative effect that gender disparity has on the entrepreneurial activities of the African women. Educated African women have continued to show great entrepreneurial development despite their social-cultural backgrounds. The level of access to education increases the entrepreneurial competency of African women entrepreneurs. The mediating factor for the research on gender inequality and entrepreneurial development is 
gender development index (GDI). The level of human development varies across various African countries. Likewise, there are great variations in the gender parity among these countries. The gender development index measures the gap in human development between women and men based on basic dimensions of health, knowledge and living standards. The effect that GDI has on women entrepreneurial activity indicates that gender inequalities affect the rate of entrepreneurial development for the African women.

African women entrepreneurs have been highly regarded in recent development reports focusing on the growing economies of the world. In Africa, the fastest growing and economically developed countries such as Nigeria, South Africa, Uganda, Zambia, and Ghana among others have the highest percentage of women entrepreneurs globally. The continent of Africa has the highest proportion of female entrepreneurs compared to other continents in the world. In the Sub-Saharan Africa region, an average of 27 percent of the women population was reported to be engaged in entrepreneurship development by the Global Entrepreneurship Monitor (GEM) women's report of the year 2012. The report indicates that Pakistan women entrepreneurs represent only 1 percent of their population compare to Zambia's 40 percent. Differences in cultural and religious factors affecting women for these two countries can be cited as the sound reason that makes such disparity exist. While entrepreneurial startup activity is high for the Sub-Saharan African woman, there is a high level of business discontinuance compared to their male counterparts, and women in other regions of the world. The most rampant reason for leaving business by women is cited as lack of profitability and finances to support their enterprises (GEM, 2014).

Entrepreneurial development of the African women is dependent on a number of variables including cultural background, religious beliefs, gender stereotyping, age, the level of access to education and social capital. In studying the relationship that gender inequality has on a population, it is best to describe the link between them using the United Nations (UN) index on gender inequality. Understanding the effects of inequality on entrepreneurship and measurement of its variability is assist in the prediction of women entrepreneurial development rate for various African countries. One of the largest contributors to gender inequality in the African continent has been the cultural norms associated with the diverse ethnicity groups of the continent (Kabeer, 2005; OECD, 2005). Religion also affects the gender balance given the various views held by different religious societies (Seguino, 2011). Elements of individualism, motivation, rationality, and self-reliance among others were considered key ethics of Modern capitalism that fostered entrepreneurship.

Some cultures have a direct link with religion since religious beliefs and basic values guide the personality of individuals. On the other hand, the culture of a person determines their ethics and values in a more conservative way. Depending on how religion values are incorporated into a culture, the overall effect that these values have in the development of entrepreneurship is closely linked to the gender parity degree that is established in the society. Culture can be greatly influenced by the social environment and it is thus acceptable to indicate that several collective phenomena control the cultural systems of a community. Cultural variances are the outcomes of ethnic, social class, religious, and language variations. It follows that the change in gender inequality indices experienced in Africa is as a result of cultural adjustments over time. The changing socialcultural dimensions such as female genital mutilation, gender-role stereotyping, and gender-based discrimination have greatly led to improvement on the gender parity gap in Africa (GEM, 2012).

In most of the African cultures, women were traditionally seen as inferior compared to men. In turn, most of the women experience sexual offenses because some African cultures dictate that women are part of the property owned by a man. Discrimination against women has also been rampant in many African countries safe for the recent development and advocacy on gender equality. Although tremendous improvement has been recorded in the gender disparity gap, there still exists a huge difference in some communities that uphold their traditional cultures to date. Other factors that affect the capacity of entrepreneurial development of the African women include their age, experience, and marital status. In the 2014 GEM special report on women in entrepreneurial activities, the relationship between age and entrepreneurship is relatively consistent around the world for both genders (29). The general pattern of entrepreneurial prevalence is low for 18-24 year-olds but highest for 25-34 year-olds. Beyond this cohort, the pattern is a decreasing one, indicating that the entrepreneurial development of the African women is not greatly influenced by the age factor.

The gender development index of the African women is greatly affected by the social-cultural background and factors such as ethnicity and self-reliance. At the individual level, most of the African women exhibit a lower rate of access to positions from where they can mobilize resources once needed. Leadership in the businesses and the political scene has been dominated by men in Africa, which is a dominant occurrence worldwide. However, looking at the number of successful women in entrepreneurial positions, there is a lower percentage of women macro-entrepreneurs in Africa compared to men. In developed nations, the ratio is reversed. Most nations have almost equal or higher percentage of women in larger business organizations compared to men. The low participation of African women in entrepreneurial activity can be attributed to social capital (Coleman, 2010). Social capital develops relationships among resources and networks that are used to mobilize such resources when needed (Dennehy, 2010). The essence of social capital is developing social relationships and networks of both tangible and intangible resources. Mobilizing resources to set up and successfully run an entrepreneurship organization requires deep social support networks to facilitate development through institutional support. 
In Africa, most traditional cultures do not support women engaging in social, political, or economic activities. The gender gap that has dominated traditional cultures has created gender inequality that has been manifested to the social settings required for entrepreneurial development. The restriction set forth by these inequalities cripples the social development capability of the women. In turn, low gender development index results to low rates of entrepreneurial development due to the lack of enabling relationships and networks. In societies with higher gender parity, women entrepreneurs get motivated towards entrepreneurship and can also gain entrepreneurial education from others. Gender development is influenced by the levels of inequality in the societies of the African women, and in turn, it affects their capability of entrepreneurial development. The difference in human development index for men and women has a mediating role in the relationship that gender inequality has with the rate of entrepreneurial development for the African women (Cattell, 2001).

According to GEM special report on women and entrepreneurship, social networking is one of the main factors that have contributed to the development of women entrepreneurial activities on the global platform (GEM, 2014). Economic-based social networks provide women with motivation, advice, contacts and other benefits that lead to a higher interest and successful development in entrepreneurship. In countries where women are less likely to be in a network relationship with an established entrepreneur, there are low entrepreneurial activities (GEM, 2014). In most of the African cultures, women have had a more backstage role in running the affairs of the society. Thus, they are associated to low economic activities that are focused on developing the family unit. Mordi, Simpson, Singh, and Okafor (2010) describes that women's priority is given to their roles as wives and mothers. The society dictates that that they should have lesser participation in entrepreneurial activities. This mindset in most of the African culture calls for women to be humble and modest and disassociates them from entrepreneurial activities.

The moderator factor in the research is the level of education of the African women. In most of the traditional African cultures, the role of the woman has been stereotyped to that of a housewife. In the recent years, the concept has greatly changed and more women are accessing education all over the African continent (GEM, 2014). Access to education dilutes the effects that traditional gender inequality has on an individual's decision. Educated African women have been on the forefront of fighting against negative traditional cultures such as early marriages, genital mutilation, and deprived access to education (Maina, 2014). On the other hand, access to education also increases the entrepreneurial competency and knowledge for the African women. Educated women have the skills and knowledge that can be applied in establishing and running a successful enterprise. Therefore, access to education increases the entrepreneurial development of African women. Education has a moderation effect on the relationship between gender inequality and rate of entrepreneurial development.

In GEM's special report, education has been indicated to have a positive influence on a person's selfefficacy and self-confidence, thus increasing the capacity of entrepreneurial development (30). The increase in skilled management ability, innovativeness, and competitiveness associated with an educated workforce consistently results to higher entrepreneurial activities. While acknowledging the Goldman Sachs 10,000 Women's project, (Coleman, 2010) reiterated that business and management education for female entrepreneurs assists in closing the gender gap in the developing countries and in turn, stimulates economic growth (16). There is higher gender parity in relation to the ratio of entrepreneurs with higher education (GEM, 2014). It indicates that increase in education level stimulates entrepreneurial activities.

\section{Research Method}

\subsection{Research Problem}

Previous researches focusing on gender and entrepreneurship for the African women has been mainly based on identifying and addressing the challenges that these women face. Spring (2009) focused how the African women have engaged in the entrepreneurial landscape indicating the differences experienced in the informal and formal business sectors (26).In a regional study on women entrepreneurial activity.

A research on gender differences in entrepreneurial performance for South Africans established that there are significant dissimilarities between the performance of male and female entrepreneurs (Neneh, Van Zyl, \& Van Noordwyk, 2016). The study measured the performance of firms established and run by female entrepreneurs against that of those run by their male colleagues. They also established that the entrepreneurial orientation varies between men and women, noting that there are gender differences in education, thus affecting their level of engagement on entrepreneurial activities (Neneh et al., 2016).

The relationship between gender and women entrepreneurial activity has been researched on a global scale (Gupta, Turban, Wasti, \& Sikdar, 2009; Henry, Foss, Fayolle, Walker, \& Duffy, 2015; Sarfaraz, Faghih, \& Asadi, 2014; Shinnar, Giacomin, \& Janssen, 2012). Entrepreneurs assessed in a study by Gupta et al. (2009) were found to exhibit more masculine characteristics (409). Gender stereotyping also makes people perceive entrepreneurs to have characteristics similar to those of males. The research also indicates that women with the mentality that they have masculine characteristics have higher entrepreneurial intentions than those who consider themselves less similar to males (Gupta et al., 2009). The outcomes indicate the effects of gender stereotyping on entrepreneurial activities of women. Gender-role stereotyping is mostly as a result of the socio-cultural settings of a society. 
Shinnar et al. (2012) indicated that gender is a significant factor in people considering engaging in entrepreneurship (480). Sarfaraz et al. (2014) researched on the relationship that exists between gender equality and women entrepreneurial activity. The study indicated that there is no significant correlation between these two variables. GEM data on 41 countries from the middle-income and high-income countries was used along gender inequality indices for the year 2007 (Sarfaraz et al., 2014). Though, the relationship was discreet between the two, notable differences exists in relation to the established businesses and gender parity. The study focused on different regions of the world without consideration of their cultural influences. Therefore, they concluded that in the economies where women have equal opportunities with men, they portray a high prevalence for entrepreneurship compared to the countries where women have ratio gender inequality.

In this research, we employ the measures of inequality to establish the link between gender inequality and entrepreneurial activity in African nations. Cultural factors greatly influence the entrepreneurial activities of the African people. Data was sourced from the global platforms that provide gender measures. The United Nations Development Program (UNDP) collects data that measures the status of human development across the world. Global Entrepreneurship Monitor (GEM) is involved with measurements of the entrepreneurial activity of various countries across the world. Using data from these two organizations, the research investigates the link between women entrepreneurial activity and gender parity across the twelve African countries covered by GEM. Among other factors, gender inequality and society setting in Africa has greatly affected women engaging in businesses in the formal sectors (Spring, 2009). Women mostly own small enterprises in these economies while they contribute a large percentage as employees of bigger entrepreneurships (African Development Group (AfDB), 2015). The research is an assessment of the effects that gender inequality has on women entrepreneurship in Africa.

The research also looks at the effect that education development has to gender inequality and rate of women entrepreneurial development. Literacy index data from United Nations Educational, Scientific and Cultural Organization (UNESCO) is used to assess the rate of education in the African countries under study. Subbarao and Raney (1995) indicated that women education increases their participation in economic activities as well as producing other social gains. Raising the level of women participation in entrepreneurship raises their social levels and thus decreases the gender gap apparent in many countries. Lack of education causes the women to be undervalued and oppressed in the society (Coleman, 2010). In African countries, this is mostly the case. Uneducated women are subjected to tasks and processes that lead to increase in gender gap between male and female Africans. However, access to education strengthens the African woman and opens up various avenues for development such as through employment and entrepreneurship. In turn, there is a reduction in the gender inequality in the society. Therefore, this research investigates whether there is a direct link between the level of education and the indices on gender parity and rate of entrepreneurial activity.

\subsection{Research Model}

\subsubsection{Research Variables}

The research uses data from GEM 2012, on women entrepreneurial activity in 12 African countries. Gender-related indices are retrieved from United Nations Development Program and other demographic online databases. Gender equality is calculated as the inverse of gender inequality index (GII). Countries with a high index in terms of GII are given lower gender equality values. The research model and variables used in the study include gender inequality index as the predictor, gender development index as the mediator, and the rate of women entrepreneurial development as the response variable. The model applies the level of education in a country as the moderating variable between the predictor and response variables.

\subsubsection{Gender Inequality Index}

The Gender Inequality Index (GII) is a measure of the position of women in the society as developed by the Global Entrepreneurship Monitor. According to GEM, Gender disparity is a major obstacle to human development. Since 1990s, there have been major strides to empower the girl child but gender equity has not yet been fully met especially in Africa. The socio-cultural drawbacks that face most African women are a major cause of inequality. In many instances, female persons are discriminated against in health services, access to education, political engagement, and employment industry among others. These actions result to negative influence on improvement of their abilities and their liberty to choose. This study uses inequality indexes of seventeen African countries to assess the relationship that gender disparity has on participation of women in businesses.

The GII is a measure of gender disparities in three imperative aspects of human development. It considers the reproductive health that is determined by maternal mortality rate and births in adolescence. Women empowerment is determined by the number of female parliamentary members as a proportion of parliamentarians aged over 25 years and have accesses education to at least the secondary level. The third consideration is economic status, which is expressed as employment industry participation. It is a measure of labor force contribution rate of female aged over 15 years. The index is designed to expose dissimilarities in the distribution of accomplishments between men and women. It establishes the human development cost of 
gender disparity. Therefore, the greater the GII rate the more the inequalities in gender for a country and it subsequently reduces the human development levels. The index indicates the position of women in the 17 African countries assessed in this study. It shows the gender gaps in these nations as a reflection of the African nations.

\subsubsection{Gender Development Index}

Gender Development Index (GDI) is a measure of the gender gap that is prevalent in human development activities. The index accounts for inequalities between the male and female genders by measuring three elementary scopes of human development. It uses the measures of health, knowledge and living standards, similar to the Human Development Index (HDI). It is a calculation of the HDI of the basis of gender for both men and women using. The index is a straight measure of gender gap that indicates the proportion of women HDI to that of men. It establishes how far women have developed when considering the seventeen countries under study.

This index indicates how much women lags behind their male colleagues and the extent to which they need to catch up within each dimension of measure. It is suitable for portraying the actual gender gap in human development which assists in formulating policies addressing inequality. In this research, GDI is used to investigate the link between gender inequality and rate of entrepreneurial development. It is thought as the mediating factor between these two factors. The GDI acts as a mediator between inequality and women entrepreneurship. Increased inequality measures f GII increases the rate of GDI, thus establishing a direct connection between the two. On the other hand, a higher GDI value leads to lower rate of development. In essence, an increase in the GII results to a decrease in entrepreneurial activity. The GDI only acts as a mediator variable between these two.

\subsubsection{Rate of Women Entrepreneurial Development}

The rate of women entrepreneurial development is indicated by the proportion of female to male business in the outlined African nations. It is given by the percentage of adult productive women who are upcoming entrepreneur or owners of a business that is more than three months old but less than forty-two months. A fundamental measurement determined by the GEM is the Total Entrepreneurial Activity (TEA) ratio. The ratio includes women in processes of establishing an entrepreneurship as well as those running for more than three months but not past three and a half years. A different measure looks into the established business proprietors that characterize people running enterprises that are older than three and a half years. TEA rates indicate the degree to which people have embraced the initiative to engage in entrepreneurial activity.

Female Total Entrepreneurial Activity indicator is used to reveal the engagement of women in entrepreneurship and establish if the country offers a suitable environment for women entrepreneurs. It is calculated as a ratio of female to male entrepreneurs of adult business owners over the age of eighteen and up to that of sixty-four years. The female TEA measure gives an overview of how women engage in economic activities compared to their male counterparts. Therefore, the ratio measures the gap between male and female entrepreneurship rate. Use of the ratio alongside GII and GDI indices allows a gender-related comparison of the effects that gender disparity has on the economic ability of African women. The study is based on the seventeen African countries covered by the GEM program.

\subsubsection{Rate of Access to Education}

To assess the rate of education in the African countries of the study, the UNESCO's literacy index on gender basis is used. The Gander Parity Index (GPI) is a measure of the proportion of the population of women with education against men for ages fifteen years and over. An index value of one reveals there is a high parity between educated men and women in a population. For values less than one, it shows that there is a disparity and that boys are favored over girls. Similarly, values greater than one is an indication that the inequality in the population is in favor of girls to boys. A shortcoming of the index is that it doesn't indicate whether development or deterioration is as a result of the performance of either males or females. The index is a measure of the progress that the society has made towards gender equality in terms of access to education or opportunities availed for women compared to those of the men. The age bracket used for the study represents where most of entrepreneurs assessed by the GEM falls.

The literacy index gives an adjusted measure of education equity in gender for a population. According to UNESCO, the index is also useful for application in evaluating the opportunities that encourage women to take part in entrepreneurial activity. The GPI is used to identify socioeconomic disparities in gender education access. The level of access to education is linked to this research as a moderator variable for gender inequality and rate of women entrepreneurial development. The higher the rate of education, the lower the gender inequality is experienced. According to England (2010) women with higher levels of education place a higher intrinsic value on economic activities such as employment and entrepreneurship. Compared to educated women, those who do not access education give motherhood a greater value compared to jobs they can access (England, 2010). 


\subsubsection{Research Hypotheses}

The research investigates the relationship between gender inequality in a country and the rate of women entrepreneurial development. The study is accomplished through a set of hypotheses. The first hypothesis links gender inequality index to the gender development index. It is theorized that gender equality is positively related to women entrepreneurial development. The statement assumes that the higher the gender equality in a population, the higher the rate of entrepreneurial development for women. Gender Inequality Index is used to assess the rate of equality in these countries. Higher index of inequality indicates a lower gender equality measure, which is then used in the correlation analysis. In the research model diagram, this hypothesis is indicated by a bold line, indicating that it connects our two main variables, predictor and outcome variable, of the research. The hypothesis statement is as follows;

- H1. Gender Equality is positively related to the rate of entrepreneurial development of the African women.

The second hypothesis is based on the implication that gender equality can be used to predict gender development index (GDI) for a population. The GDI as a measure of human development is greatly affected by gender inequality. The higher the gender inequality, the lower the development rate of women thus leading to a lower index value for GDI. Gender inequality affects social and economic activities used to measure the GDI. Lower gender equity in a society is accompanied by poor health and education services to women. Access to these fundamental development processes are also limited to women in such societies. It also affects the living standards of the women, thus lowering the GDI index in totality. In the hypothesis, it is stated that the higher the gender equality measures in a population, the higher the rate of gender development. The assumption is indicated by the arrow labeled $\mathrm{H}_{2}$ in Figure 1. It connects the predictor variable to the mediating variable of the research. This statement is hypothesized by;

- H2. Gender Equality is positively related to the Gender Development Index.

The third hypothesis of the study connects the gender development index (GDI) to the rate of women entrepreneurship. It is posited that a higher value on the GDI index results to a higher entrepreneurial rate. Increased women development leads to empowerment of the female gender. The empowered women are in a better position to engage in economic activities compared those in countries with a lower development index. Therefore, a higher GDI value predicts that more women are engaged in entrepreneurial activities in a country. Entrepreneurial intentions are increased by access to education, higher living standards as well as healthier conditions. These aspects indicate a higher GDI index since they are used to assess the human development index used in GDI. The relationship between entrepreneurship and GDI is in a positive direction. As shown in Figure 1, the arrow linking the two is labeled as H3. This hypothesis is stated as;

- H3. Gender Development Index has a positive relation to the rate of entrepreneurial development.

The fourth hypothesis identifies the effect that the level of education has on gender inequality and women entrepreneurship. The dotted line connecting the fourth variable to our research model indicates a moderating effect of the level of education. Access to education increases the rate of entrepreneurship and lowers the gender gap in a society. In essence, high levels of education are hypothesized to lower the gender gap of a country. With lower gender gap, women are able to engage in economic activities that aid in human development. Therefore, the GDI index is raised allowing more women to participate in entrepreneurship. At the same time, access to higher levels of education increases the entrepreneurial intentions and competency of African women entrepreneurs. The moderating hypothesis as stated as;

- H4. The level of education is positively related to Gender Equality as well as to the rate of entrepreneurial development.

H1

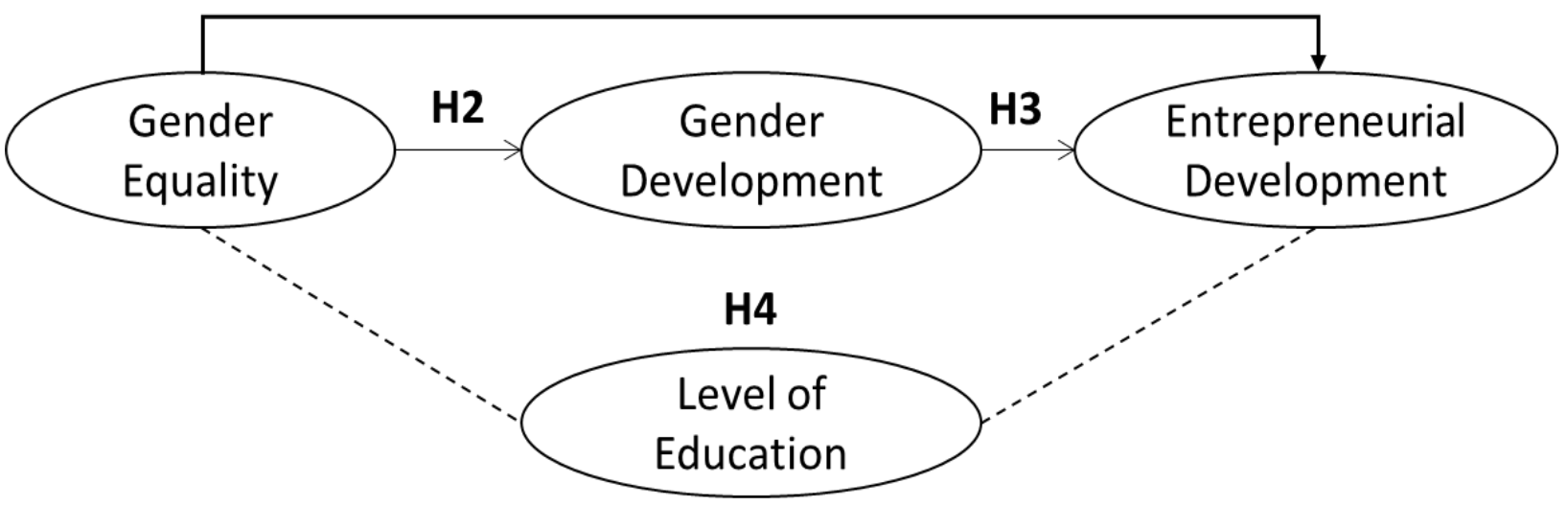

Figure-1. Research Model Diagram. 


\section{Methodology}

\subsection{Data Collection}

Women entrepreneurial activity data were sourced from the Global Entrepreneurial Monitor surveys. The data used indicates the proportion of women entrepreneurial activity to those of men for ages above eighteen years. Gender Inequality and gender development indices were sourced from the United Nations Development Program data hub. The indices are regularly measure by the organization as a measure of gender gap differences in countries. The gender parity index in education is measured and updated by the institute of statistics in UNESCO. The index is a measure of the proportion of women in access to education against that of men for ages above fifteen years of age.

\subsection{Data Analysis}

This experimental research investigates whether gender equality increases the rate of women entrepreneurial development. It also examines the effects that gender development and gender parity in education has to this relationship. A correlation analysis was carried out to establish the linkage between gender inequality index and the women entrepreneurial activity, gender development index, and gender parity index in education. Likewise, women entrepreneurial activity rate was correlated against gender development index and gender parity in education. The data obtained from GEM women entrepreneurial activity survey, UNDP gender parity indices, and UNESCO literacy index were analyzed by use of SPSS software. The seventeen African countries in the study were selected according to the data available from GEM. The results of the correlation analysis were analyzed and discussed in the following sections.

\section{Results}

\section{Results Based on Entrepreneurship Percentage in Africa}

GEM report released in 2015/2016 covers seven African countries where entrepreneurship among women is low due to various factors of culture, religion and education among others. Entrepreneurship age according to GEM is18 -64, this is the age between which individuals are expected to develop entrepreneurship intentions. According to the report lower percentage of women have the intentions between this age brackets

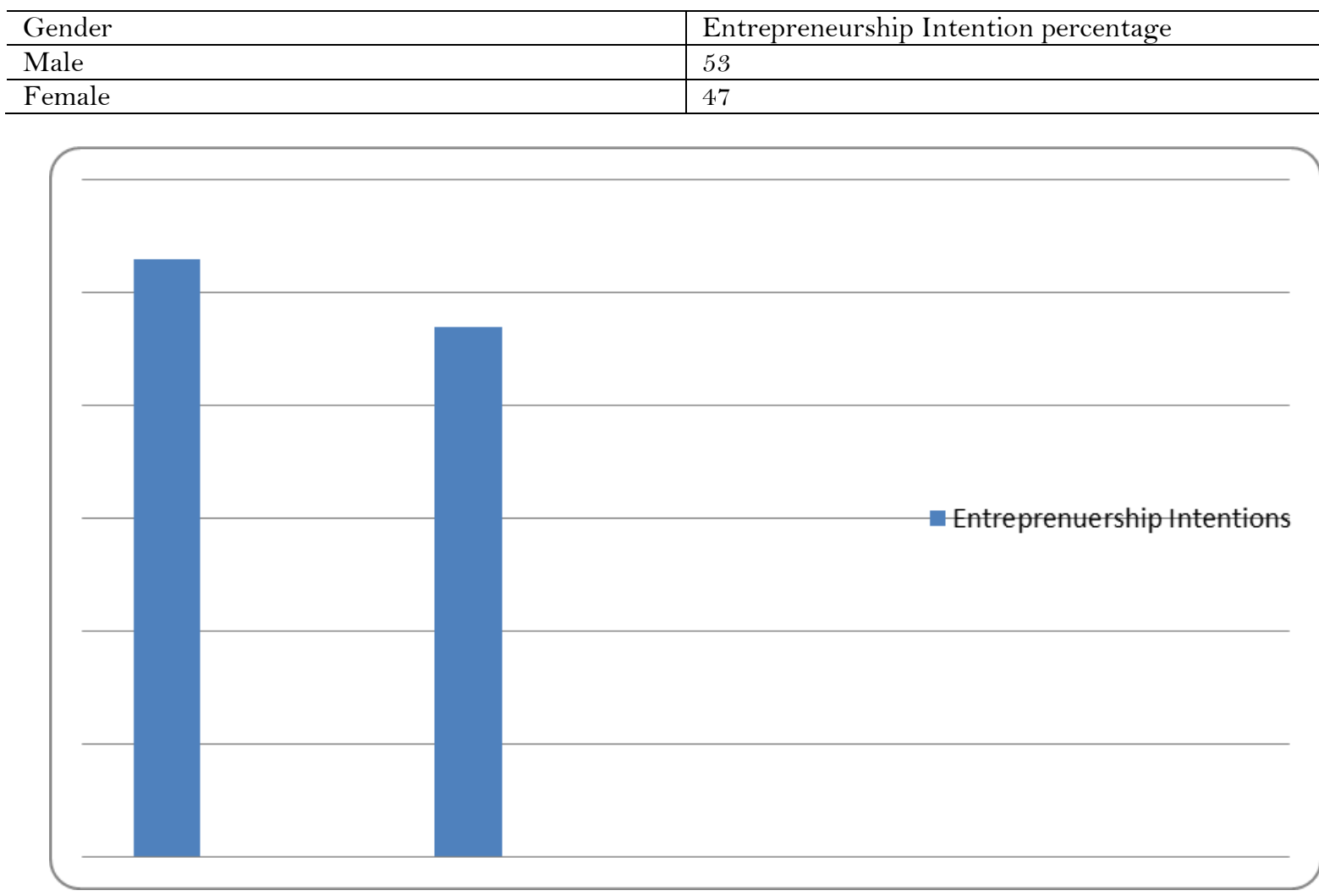

\section{Results Based Factors influencing Entrepreneurship}

Entrepreneurship among women in Africa remains a challenge due to various factors. Seven African Countries sampled in the GEM report considered a population of 2000 women in each country. The results as portrayed by the table and graph below is an indication that improving entrepreneurship among women in Africa must entail fighting or beating some of factors which are outdated. 


\begin{tabular}{l|l|l|l|l|l}
\hline Countries & $\begin{array}{l}\text { Religious } \\
\text { Beliefs }\end{array}$ & $\begin{array}{l}\text { Cultural } \\
\text { Background }\end{array}$ & $\begin{array}{l}\text { Gender } \\
\text { Stereotyping }\end{array}$ & $\begin{array}{l}\text { Level of access } \\
\text { to education }\end{array}$ & Social Capital \\
\hline South Africa & $30 \%$ & $51 \%$ & $24 \%$ & $15 \%$ & $40 \%$ \\
\hline Angola & $45 \%$ & $49 \%$ & $28 \%$ & $20 \%$ & $44 \%$ \\
\hline Ghana & $47 \%$ & $50 \%$ & $26 \%$ & $18 \%$ & $46 \%$ \\
\hline Nigeria & $48 \%$ & $48 \%$ & $23 \%$ & $17 \%$ & $48 \%$ \\
\hline Zambia & $45 \%$ & $49 \%$ & $22 \%$ & $14 \%$ & $42 \%$ \\
\hline Bukinafaso & $49 \%$ & $44 \%$ & $21 \%$ & $16 \%$ & $43 \%$ \\
\hline Botswana & $48 \%$ & $43 \%$ & $20 \%$ & $17 \%$ & $46 \%$ \\
\hline Average & $\mathbf{4 4 . 5 7 \%}$ & $\mathbf{4 7 . 7 1 \%}$ & $\mathbf{2 3 \%}$ & $\mathbf{1 6 \%}$ & $\mathbf{4 3 . 7 1 \%}$ \\
\hline
\end{tabular}

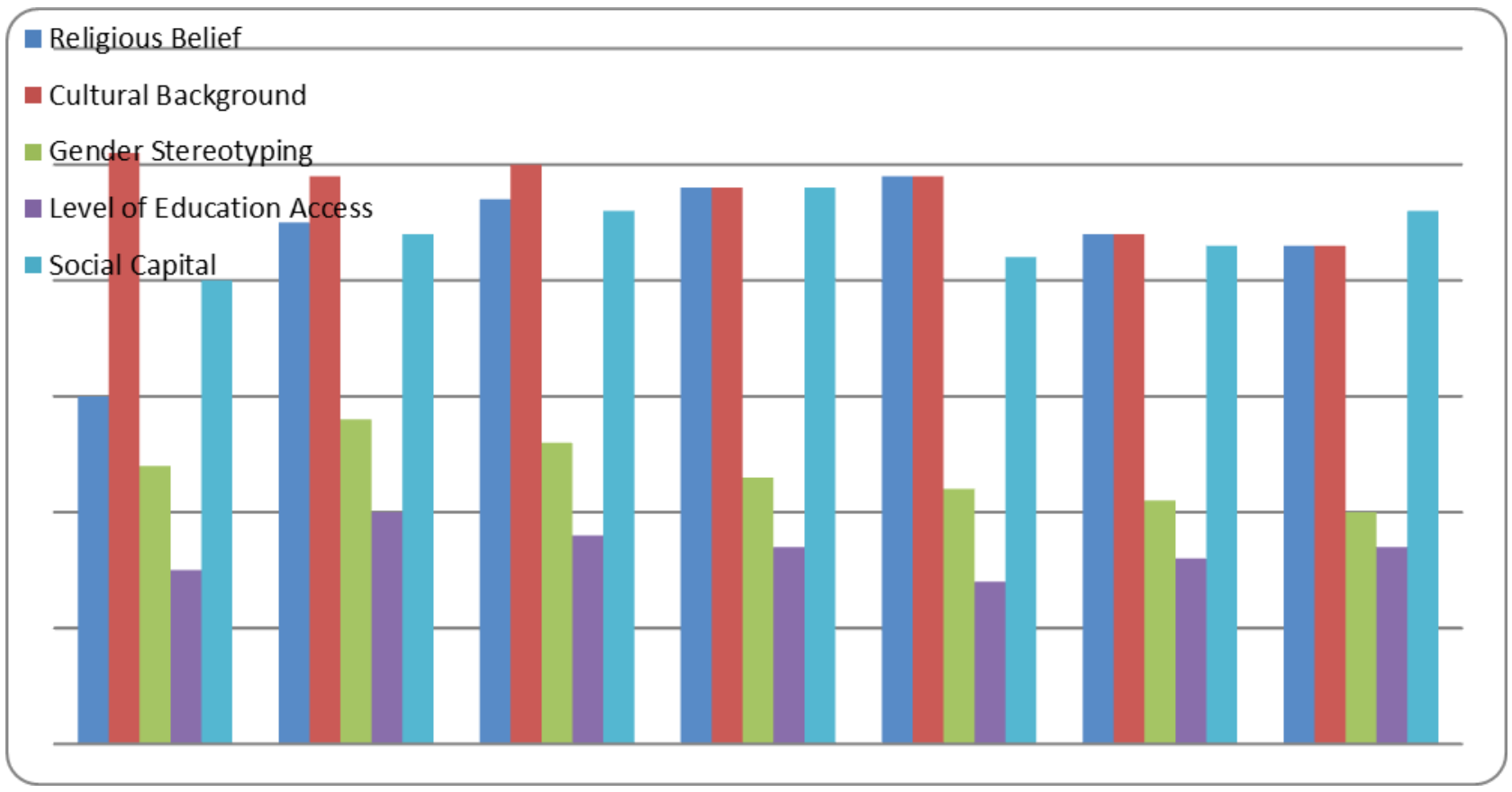

\section{Results Based on Religious Believes}

Religious believes is a major factor among African countries and other parts of the world. The results below are an indication that some of the religious believes in Africa derail the power of entrepreneurship among African women. It is worth noting that Christianity and Islam marks a larger percentage of the population, the table below indicates results based on religious factors influence on Entrepreneurship intentions among women.

\begin{tabular}{l|l}
\hline Countries & Entrepreneurship \\
\hline South Africa & $43 \%$ \\
\hline Angola & $44 \%$ \\
\hline Ghana & $46 \%$ \\
\hline Nigeria & $45 \%$ \\
\hline Zambia & $47 \%$ \\
\hline Bukinafaso & $48 \%$ \\
\hline Botswana & $42 \%$ \\
\hline
\end{tabular}




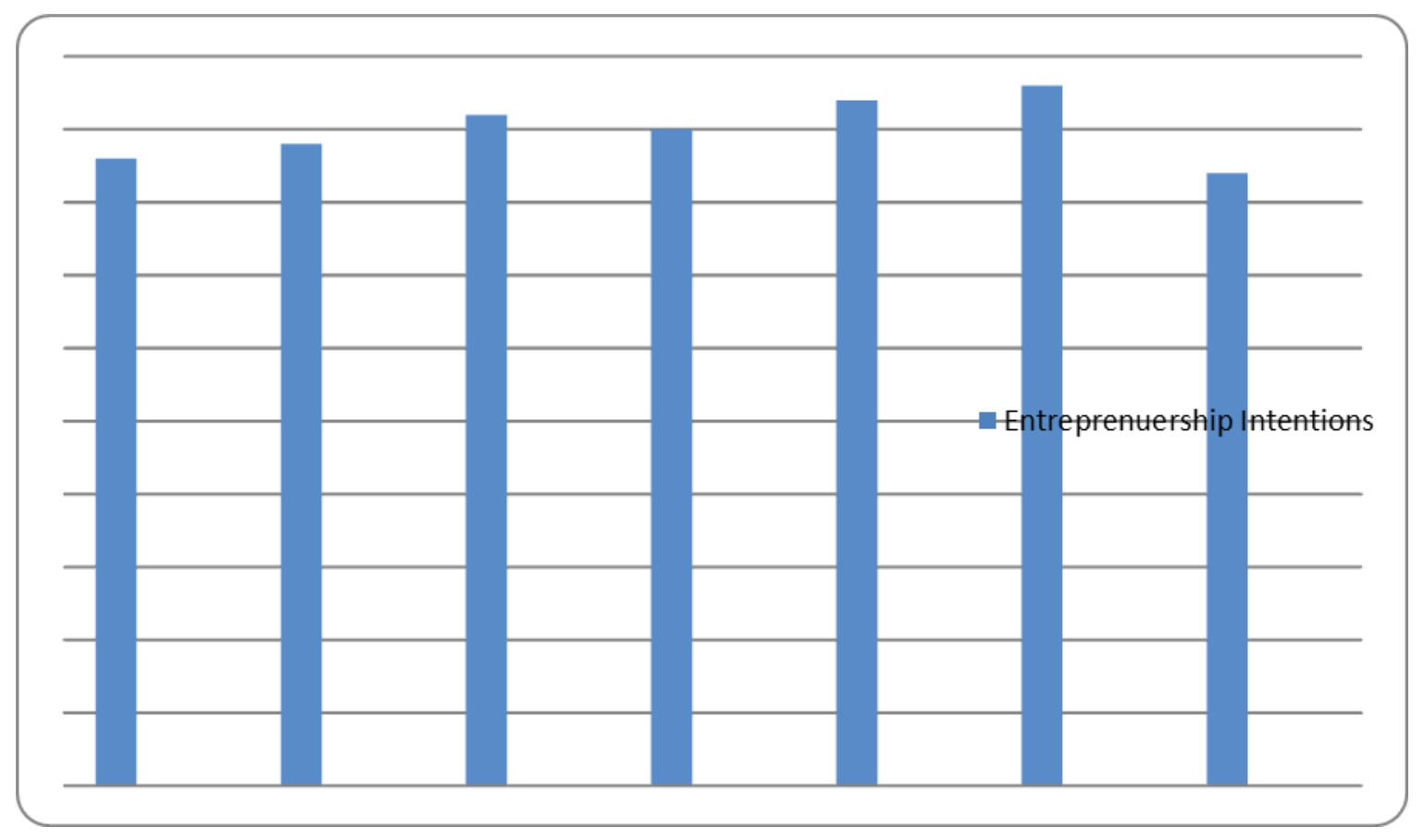

\section{Discussion}

Entrepreneurship is considered among the pillars of poverty eradication in the modern society. Based on the value accorded to entrepreneurship, it is important that both genders take part in its practice. From the obtained results, it is clear that women are not into entrepreneurship as expected; this has prompted studies into the factors leading to this kind of disadvantage.

The results of the study clearly indicate that cultural background is the main undoing or influencing factor towards women entrepreneurship. According to sampled population, most women in the seven African countries are of the opinion that their culture gives main the obligation to provide for their families any all ways thus they are rightfully charged with the responsibility of being entrepreneurs. In this case most women among African countries are not confident on delivering or doing well when it comes to entrepreneurship or putting businesses. Some of the African cultures noted in the seven countries prohibit women from taking part in entrepreneurship activities or allow them to lower extent. As compared to continents, African cultural background is the main reason why women in Africa are yet to reach or match women from other continents. It is important that cultural backgrounds of negative elements or backward nature be eradicated to allow entrepreneurship across all genders. Considering the age entrepreneurship intentions (18-64), most African lack the free decision will at the age of 18 hence most of the start entrepreneurship activities a bit later or at older stages. Whereas some the cultures among African countries prohibit women from taking part in entrepreneurship aspects, others delay the take of entrepreneurship oriented women. It is therefore vital that cultural barriers be limited to other areas that do not affect economic well-being of populations. Cultures among African countries are deeply rooted in the villages and indication that less entrepreneurship due to culture in the villages is the reason for poverty in these villages. In order to open up the villages and empower women, it is necessary to let the men understand the strength of women and how vital it is when they are converted to entrepreneurs. Based on the duties allocated or left to the women in the villages, it is clear that women are smart and enduring thus can shoulder challenges in any field.

As stated before, cultural background is a powerful network that needs real empowerment to break. The kind of links associated with cultural background as brought about the results is one of serious concern. Some cultures enjoy direct link with religion since religious beliefs and basic values take control of the personality of individuals. On the other hand, the culture of a person determines their ethics and values in a more conservative way. The results indicate that religions that base their beliefs on the caste system, fate, excessive ritualism, and magical reliance negate the essence of hard work, and hence greatly affecting the entrepreneurial activities of the believers. It is thus true to say that religion affects the cultural belief systems of various cultures. Depending on how religion values are incorporated into a culture, the overall effect that these values have in the development of entrepreneurship is closely linked to the gender parity degree that is established in the society. However, it is notable that culture is not entirely shaped by religion. Culture can be greatly influenced by the social environment and it is thus acceptable to indicate that several collective phenomena control the cultural systems of a community. Cultural variances are the outcomes of ethnic, social class, religious, and language variations. Advanced studies also indicated that changes in culture occur over a period of time under influences of the social settings. It follows that the change in gender inequality indices 
experienced in Africa is as a result of cultural adjustments over time. The changing social-cultural dimensions such as female genital mutilation, gender-role stereotyping, and gender-based discrimination have greatly led to improvement on the gender parity gap in Africa.

Women are coming out to be good leaders and managers in organizations across the globe thus making it necessary to give them opportunities towards management.

A research on gender differences in entrepreneurial performance for South Africans established that there are significant dissimilarities between the performance of male and female entrepreneurs. The study measured the performance of firms established and run by female entrepreneurs against that of those run by their male colleagues.

They also established that the entrepreneurial orientation varies between men and women, noting that there are gender differences in education, thus affecting their level of engagement on entrepreneurial activities. In an attempt to link culture, gender and entrepreneurship, the cultural factors that affect women's involvement in entrepreneurship was investigated. Gender differences were noted to significantly affect the level of involvement of women in enterprise activities. The low engagement was attributed to ethnic cultural influences for the women under study.

Religion is another factor that dominates our societies; it is believed that apart from cultures, religious believes also dictate daily activities with the societies.

Religion is ranked among movements or reference groups that determine the way member of a group conduct themselves. Based on the results obtained among the seven African countries, men or male gender is highly empowered. A survey conducted in most business premises owned by families members reveal that women are mere caretakers and not decision makers. A number of them reveal that any aspect of the business must be drawn from the male counterpart.

When asked why women are mere caretakers on such businesses, most of them made references to holy books and various religious doctrines. The doctrines identifies the male counterpart as the ones in charged thus women give way for the man to take charge. In order to obtain more on the extent of influence accorded religion, the survey opted to enquire whether the women in these regions had intentions of changing or walking out the doctrines to change their status.

The results was negative with most women point out severe consequences if the dare defy the doctrines of their religions. Religion with severe doctrine on women is deeply rooted in the local areas or villages. From the severe, it is necessary for all parts of Africa to embrace modern aspects of life where equality is prevailing. In areas where equality is fully embraced, the locals have realized the potential in women when it comes to business operations and are thus empowering women from all areas to help steer success.

Entrepreneurship requires the power of social connection to penetrate the world. This brings in the vital tool or factor social capital.

Women in the modern society need social connection to grow as entrepreneurs. In most African countries women lack the power take charge, this because most opportunities are geared towards men. According to the study less concern is directed to women when it comes to allocations. From the survey, a number of women in the villages have will and ability to achieve as entrepreneurs yet capital needed to expose is limited. According to them, their male counterparts are well informed and have access to entrepreneurship avenues.

Entrepreneurship entails effective management; survey of organizations managed by women reveal success and well organized operations.

This brings the vital factor of access to education. For a long time women in Africa have never had good access to education, lower level of access to education remain vital when it comes entrepreneurship among women. Most communities among the seven countries have realized the need to give the female gender access to education. As much as some still face challenges, access to education is the real key towards the journey of becoming entrepreneurs.

The survey conducted in the seven countries reveal that most African women access basic education thus limiting them to lower or middle level management roles. Exposed African women are right into ensuring more women entrepreneurs are produced to take opportunities and mentor the rest. Education among African has been low as compared to other continents, according to the sampled respondents, cultures and religious believes have derailed the expected education access among African women.

Throughout the study, most of the respondent reveals that it has taken the intervention of some special bodies like nongovernmental body to see some the most powerful women through education system. Most of the women found in the villages are blaming their limited exposure to poor access to education thus calling for improved system to incorporate more women to steer their entrepreneurship bid.

\section{Conclusion and Recommendations}

Entrepreneurship is a pillar of any successful society. However attaining an entrepreneurship steered society is not achievable without gender equality.

According to the study, it is important note that women remain key part of the society hence the need to push them to be entrepreneurs. As much more women are coming out to take up key roles in the society, the study points out the fact that more women are still unsure of their capabilities as entrepreneurs as a result of 
various factors within the society. As much the modern society perceived to be well informed, the report is revealing that most African countries still starve other genders of information needed to steer them to greater success heights.

Communities in the modern society have embraced globalization thus allowing free movement and collaboration with others in other parts of the world as well. It is important that communities in these sampled countries fully embrace globalization to allow operations with minimal doctrines as well as cultures that limit them to their villages.

There is need to break cultures and religions that derail the potential of African women when it comes entrepreneurship. Globalization is the only way that will open up the communities that still operate under isolated cultures portraying them as people in different parts of the world.

Through entrepreneurship, every part of the world is bound to enjoy steady development thus all must work towards this. As opposed to other times, entrepreneurship is presented to people in varied stages or classes to accommodate ever able member of the society.

This implies that not only women with high education status can make good entrepreneurs. As a result of this, special education to improve or better basic education is vital to place women who missed out on certain aspects at some stages catch up with the rest.

In most African countries entrepreneurs are viewed or made at families this drawn from the fact that most African managers manage or take charge of family businesses. This brings a wakeup call to families to consider empowering women through capital and education to allow them take charge and grow.

\section{Recommendations}

Women entrepreneurship is idea which must be embraced across Africa and other parts of the world. For a long time women entrepreneurship performance is below par arousing the need to fight obstacles promoting this. In order to achieve effective entrepreneurship among African women, the following will form part of the journey;

1. Social education and empowerment on outdated cultures.

2. Embracing revised religious doctrines that empower all regardless of gender.

3. Empowering women through basic, higher and special education to promote their skills or entrepreneurship.

4. Help focused women raise or build social connection needed to scale heights.

The recommendations above are not aimed at discriminating or despising any religion or cultural backgrounds but pointing the need to have the revised and steer opportunities for all with the societies. The study is mainly focused on achieving an equal society where everyone despite the gender aspect can steer the society to any desired level.

\section{References}

African Development Group (AfDB). (2015). Empowering African women: An agenda for action. Africa Gender Equality Index 2015: African Development Bank Group.

Cattell, V. (2001). Poor people, poor places, and poor health: The mediating role of social networks and social capital. Social Science \& Medicine, 52(10), 1501-1516.

Coleman, I. (2010). The global glass ceiling: Why empowering women is good for business. Foreign Affairs, 13-20.

Dennehy, J. (2010). Gender and competition: A dynamic for managers. Doctoral Dissertation, The London School of Economics and Political Science (LSE).

England, P. (2010). The gender revolution: Uneven and stalled. Gender \& Society, 24(2), 149-166.

Gupta, V. K., Turban, D. B., Wasti, S. A., \& Sikdar, A. (2009). The role of gender stereotypes in perceptions of entrepreneurs and intentions to become an entrepreneur. Entrepreneurship Theory and Practice, 33(2), 397-417.

Henry, C., Foss, L., Fayolle, A., Walker, E., \& Duffy, S. (2015). Entrepreneurial leadership and gender: Exploring theory and practice in global contexts. Journal of Small Business Management, 53(3), 581-586.

Kabeer, N. (2005). Gender equality and women's empowerment: A critical analysis of the third millennium development goal 1. Gender \& Development, 13(1), 13-24.

Maina, L. W. (2014). Women's empowerment through education in Africa: A case study of UNESCO. Doctoral Dissertation, University of Nairobi.

Mordi, C., Simpson, R., Singh, S., \& Okafor, C. (2010). The role of cultural values in understanding the challenges faced by female entrepreneurs in Nigeria. Gender in Management: An International Journal, 25(1), 5-2 1.

Naudé, W. (2013). Entrepreneurship and economic development: Theory, evidence and policy. Evidence and Policy. IZA Discussion Paper No. 7507.

Neneh, B. N., Van Zyl, J. H., \& Van Noordwyk, M. A. (2016). Gender differences in entrepreneurial orientation and performance: Evidence from South Africa. Paper presented at the Southern African Institute of Management Scientists. 28th Conference.

OECD. (2005). Culture, gender and growth, OECD development centre, policy insights \#15, Paris, France.

Olutunla, G. T. (2001). Entrepreneurship for economic development. Inaugural Lectures Series, 27, 1-64.

Sarfaraz, L., Faghih, N., \& Asadi, M. A. (2014). The relationship between women entrepreneurship and gender equality. Journal of Global Entrepreneurship Research, 4(1), 2-11. 
Seguino, S. (2011). Help or hindrance? Religion's impact on gender inequality in attitudes and outcomes. World Development, 39(8), 1308-1321.

Shinnar, R. S., Giacomin, O., \& Janssen, F. (2012). Entrepreneurial perceptions and intentions: The role of gender and culture. Entrepreneurship Theory and Practice, 36(3), 465-493.

Spring, A. (2009). African women in the entrepreneurial landscape: Reconsidering the formal and informal sectors. Journal of African Business, 10(1), 11-30.

Subbarao, K., \& Raney, L. (1995). Social gains from female education: A cross-national study. Economic Development and Cultural Change, 44(1), 105-128. 